\title{
False hope for Canadians who study medicine abroad
}

$\mathrm{E}$ very year many Canadians go abroad for medical training. About three-quarters of them are unsuccessful applicants to Canadian medical schools. Currently, almost 3600 Canadians are studying medicine at schools in the United Kingdom, Australia, Poland, the Caribbean and elsewhere. Most hope eventually to practise in Canada. Will they succeed? Should they?

It is not easy to get from a foreign medical degree to medical practice in Canada, and many of these graduates may hold misconceptions about the process and the prospects.

To enter practice in Canada, they must complete the MCCEE and the MCCQE (Medical Council of Canada Evaluating and Qualifying Examinations) and a minimum of two years of Canadian residency training. In 2013, over 1100 Canadians studying abroad registered for the 2014 Canadian Resident Matching Service R-1 (first-year) match. Yet current policies dramatically limit the number of postgraduate training opportunities for Canadians who have studied medicine abroad. There are 3282 first-year residency positions available annually, but over 2900 are taken up by graduates of Canadian schools. And Canadians who choose to study at foreign medical schools enjoy no advantage over other foreign medical graduates in this process.

The policy may seem patently unfair, but it is actually quite understandable. Many countries have developed good quality medical schools as part of a strategy for attracting foreign currency. Almost 150 schools in over 60 countries are training Canadian students. Without a policy to limit residency positions, Canada could quickly become flooded with returning medical school graduates (not to mention the astronomical cost of funding all those additional residencies).

But doesn't Canada face a shortage of physicians? In fact, over the past 15 years, medical school enrolments in

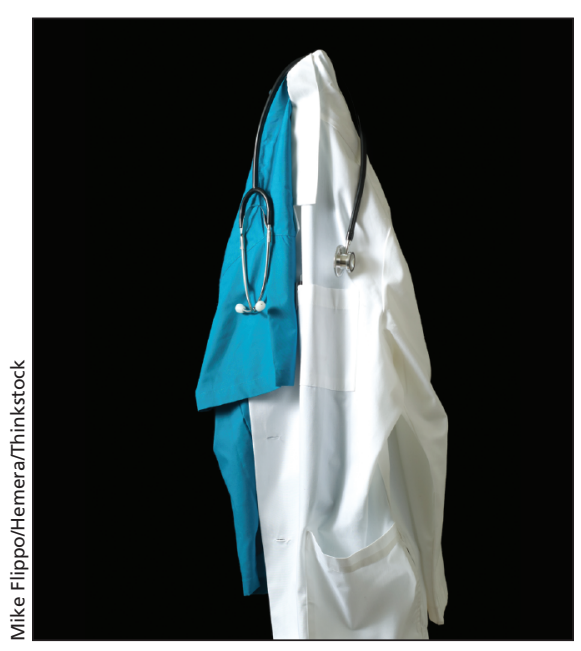

Canada have increased $85 \%$, from about 1575 in $1997 / 98$ to over 2900 in 2012/13. Between 2008 and 2012, physician supply increased $4 \%$ per year, three times faster than the Canadian population. And this trend will continue for at least the next few decades, even without more foreign-trained Canadian doctors. At the same time, the number of foreign medical graduates (including Canadians) entering practice annually in Canada has also risen consistently, from 413 in 2000 to 910 in 2011. For those who monitor Canadian physician resource policy, recent reports of unemployed graduates of Canadian medical schools are thus no surprise.

No health care system can afford to carry an open-ended liability to reimburse an ever-increasing physician supply, particularly given the ambiguity in evidence linking physician supply to population health in the developed world.

None of this changes the fact that Canadians who live in remote regions, or who seek services from less popular or less well-paid specialties, may have difficulty finding care. But this problem cannot be mitigated by increasing supply in an essentially unmanaged system where physicians can practise what they want, where they want, when they want. Although certain segments of our health care system, particularly long-term and continuing care, are underprepared for the increasing needs of an aging population, Canadian studies have consistently shown that demographic change adds only about $0.5 \%$ annually to per capita use of physician services.

Some argue that many more physicians will be needed because of the feminization of the Canadian physician workforce. Female physicians work fewer hours than men over their careers. Moreover, young physicians of both sexes are working fewer hours than their predecessors. Yet expenditures per physician in Canada (adjusted for fee changes) have nevertheless been rising rapidly.

Given all of this, it seems unlikely that more residency positions will be made available for Canadians who study abroad any time soon; nor should they be. Canadians who attend foreign medical schools must have realistic expectations about their prospects for entering practice in Canada. In the 1970s and 1980s, government policy reactions to increasing medical cost pressures included impeding the flow of medical graduates into Canada. Given the dramatic increase in domestic training, it would not be a surprise to see new government policies with similar intent soon. This time, many more Canadians would be affected. It would seem reasonable for policy-makers in both government and medicine to be crystal clear about the prospects for foreign-trained Canadian physicians expecting to return to Canada to practise. Anything less seems irresponsible and invites understandable backlash from disillusioned students and their families.

\section{Morris L. Barer PhD \\ Robert G. Evans PhD \\ Lindsay Hedden $\mathrm{PhD}(\mathrm{c})$ \\ Centre for Health Services and Policy \\ Research \\ University of British Columbia \\ Vancouver, BC}

